\title{
DESENVOLVIMENTO DE HABILIDADES NO ENSINO DE CIÊNCIAS E O PROCESSO DE AVALIAÇÃO: ANÁLISE DA COERÊNCIA
}

\section{The development of skills in science teaching and the assessment process: the analysis of coherence}

\author{
Poliana Flávia Maia ${ }^{1}$ \\ Rosária Justi ${ }^{2}$
}

\begin{abstract}
Resumo: Documentos sobre educação em ciências ressaltam a necessidade de inserção do estudante em seu processo de aprendizagem, defendendo a necessidade do desenvolvimento de habilidades, sobretudo aquelas associadas ao processo de investigação científica, com o objetivo de contribuir para o desenvolvimento de uma visão mais ampla da ciência e um conhecimento de como ela é construída e usada. Considerando a necessidade de avaliar os conhecimentos dos estudantes de forma coerente com esta nova perspectiva de ensino, este trabalho apresenta um panorama de algumas avaliações em massa desenvolvidas em todo o mundo. As questões de ciências de suas últimas versões foram analisadas de forma a subsidiar uma discussão sobre em que medida elas se aproximam ou se afastam das diretrizes contemporâneas propostas para o ensino de ciências. A análise evidenciou a dificuldade de avaliação de algumas habilidades de investigação e a existência de poucas oportunidades para a explicitação de conhecimentos a elas relacionados.
\end{abstract}

Palavras-chave: Desenvolvimento de habilidades. Avaliação. Ensino de ciências.

\begin{abstract}
Documents about science education point out the need for engaging students in their learning processes, and defend the relevance of the learning of skills, mainly those associated with the process of scientific investigation. This paper aims to contribute to the development of a wider vision of science and knowledge as it is built and used. Assuming the need to evaluate students' knowledge in a way that is coherent with this new teaching perspective, this paper presents an overview of some evaluations from all over the world. Science questions from the last versions of such evaluations were analysed in order to base a discussion about how they follow the new guidelines for science teaching. The analysis made it evident that it is difficult to assess some skills and there is an absence of opportunities to express the knowledge related to them.
\end{abstract}

Keywords: Development of skills. Assessment. Science teaching.

${ }^{1}$ Química. Doutoranda em Educação. Docente, Departamento de Química, Centro de Ciências Exatas, Universidade Federal de Viçosa (UFV). Viçosa, MG. <poliana.ferreira@ufv.br>

${ }^{2}$ Química. Doutora em Educação. Docente, Departamento de Química, Centro de Ciências Exatas, Universidade Federal de Minas Gerais (UFMG). Belo Horizonte, MG. <rjusti@ufmg.br>

\footnotetext{
${ }^{1}$ Rua PH Rolfs, s/n

Centro - Viçosa, MG

$36.570-000$
} 
Maia, P. F.; Justi, R.

\section{Introdução}

\section{Perspectivas atuais para o ensino de ciências}

A atual demanda por um conhecimento de ciências integrado à realidade e às ações cotidianas dos indivíduos tem direcionado as diversas propostas de mudanças realizadas no ensino desta área de conhecimento. $\mathrm{O}$ ensino de ciências, como defendido por diversos documentos (BRASIL, 1999b; AAAS, 1989; MILLAR, OSBORNE, 1998), deve corresponder às demandas do mundo atual, ultrapassando os limites de um conhecimento meramente declarativo e desenvolvendo um conhecimento aplicável e contextualizado. Além disso, ele deve enfatizar os caminhos e processos da ciência, contemplando não apenas seus resultados, mas, antes de tudo, seus meios. Diversos estudos na área de ensino de ciências (FERREIRA, 2006; BORGES, 2002; BARAB et al., 2000; CLEMENT, 2000) têm apresentado o potencial do uso de atividades investigativas para o desenvolvimento do conhecimento sobre o processo de investigação científica.

O processo de investigação na ciência merece especial atenção em sua abordagem no ensino, por se tratar do processo de construção da própria ciência. Os estudos conduzidos sobre o ensino do processo de investigação científica apontam para a necessidade de inserção do aluno em atividades que promovam o desenvolvimento desse conhecimento de maneira ativa, isto é, atividades em que o aluno conduza ativamente uma investigação. Isto pode permitir não só o desenvolvimento do conhecimento sobre como a ciência é construída, mas também pode proporcionar o desenvolvimento de habilidades durante a condução do processo. Identificar princípios da ciência e usá-los no processo de investigação são práticas científicas essenciais requeridas para a aprendizagem sobre a ciência.

\section{Habilidades envolvidas em atividades de investigação}

O conhecimento sobre a ciência e sua construção e o desenvolvimento de habilidades do pensamento científico são desenvolvidos no processo de ensino por meio de quatro demandas fundamentais: "saber o quê", "saber como", "saber por que", e "saber quando e onde aplicar o conhecimento" (IES, 1997). Estas demandas mobilizam tanto o conhecimento declarativo (saber o quê - em que os estudantes devem conhecer e raciocinar com base em fatos científicos básicos, conceitos e princípios); conhecimento procedimental (saber como - em que os estudantes devem saber aplicar os princípios, fatos e conceitos no processo de "fazer ciência"); conhecimento esquemático (saber por que - em que os estudantes devem saber explicar e predizer fenômenos, entendendo como e por que alegações científicas são validadas, explicando e raciocinando com modelos), e conhecimento estratégico (saber quando e onde aplicar - em que os estudantes devem aplicar seu conhecimento em novas situações e problemas).

Segundo Schwarz e White (2005), as etapas envolvidas em um processo de investigação podem ser representadas esquematicamente como na Figura 1. Este esquema torna possível uma análise e planejamento mais detalhados desse processo (sobretudo em relação às atividades de investigação planejadas para o ensino) e, conseqüentemente, uma previsão em relação às ações e habilidades requeridas do sujeito em cada etapa da investigação. 


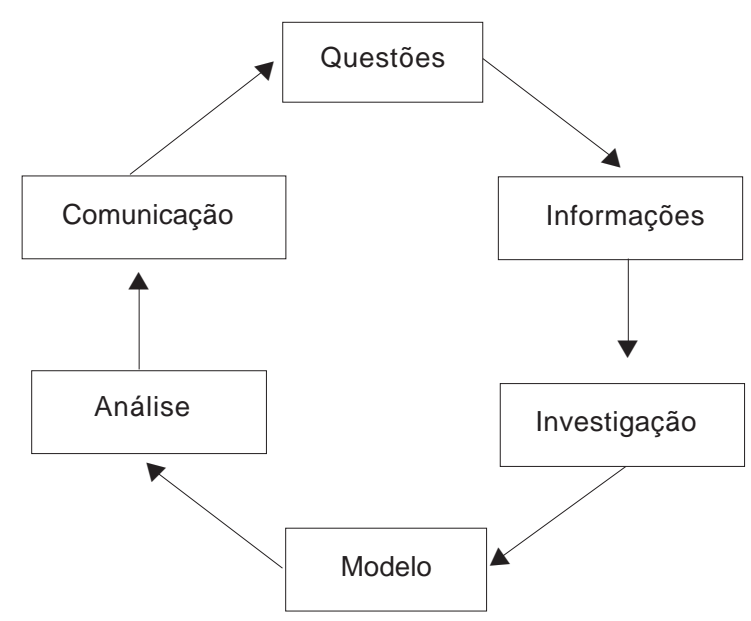

Figura 1. Ciclo de investigação (SCHWARZ, WHITE, 2005).

Conforme apresentado na Figura 1, o processo de investigação é iniciado por questões, que são formuladas com base na análise e compreensão da situação problema, delimitando o que se deseja investigar. A partir daí, é necessária a busca de informações e a condução de procedimentos específicos (testes, experimentos, entre outros) no sentido de se testarem hipóteses ou se fornecerem novos elementos sobre o sistema em estudo. As informações obtidas devem ser interpretadas e relacionadas, buscando subsidiar a elaboração de respostas às questões iniciais, propostas em forma de modelos. A validação e o reconhecimento desses modelos como produtos do processo de investigação devem ser feitos mediante sua comunicação à comunidade científica, etapa fundamental no processo de construção da ciência. Esta última etapa pode contribuir fornecendo novos elementos sobre o problema, podendo haver uma continuidade no ciclo, em que o processo será novamente desenvolvido, proporcionando o progresso da ciência.

É importante observar que o produto do processo de investigação descrito pelo ciclo acima é um "modelo" . Isto é coerente com o processo do desenvolvimento científico, uma vez que os modelos estão na base das pesquisas científicas e, ao mesmo tempo, são os principais produtos da ciência (GILBERT, BOULTER, ELMER, 2000). Desta maneira, o conhecimento sobre o papel, a construção e o uso dos modelos merece especial destaque no desenvolvimento do conhecimento em ciências.

\footnotetext{
${ }^{3}$ Em Ciências, um modelo pode ser definido como uma representação parcial de um objeto, evento, processo ou idéia, que é produzida com propósitos específicos como, por exemplo: facilitar a visualização, fundamentar a elaboração e teste de novas idéias, possibilitar a elaboração de explicações e previsões sobre comportamentos e propriedades do sistema modelado (GILBERT, BOULTER, ELMER, 2000).
} 
Contudo, esta representação do processo de investigação é bastante simplificada, uma vez que o processo de investigação não é, necessariamente, tão direto ou resumido, podendo haver movimentos contrários aos representados no ciclo, com retornos a etapas anteriores, dependendo do progresso e sucesso em cada etapa.

Esta representação do processo de investigação não busca remeter ao estudo de um "método científico", tão recorrente no ensino tradicional de ciências, que engessa as etapas envolvidas na construção do conhecimento como um algoritmo a ser seguido. Esse "método científico", adequadamente criticado na atualidade, não está de acordo com o real processo de construção de ciência, passando uma idéia incoerente da mesma (BORGES, 2002; BROOK, DRIVER, JOHNSTON, 1989). A representação do ciclo de investigação tem apenas o objetivo de explicitar, de maneira geral, as etapas mais freqüentemente empregadas em um processo de investigação, com o propósito de permitir uma reflexão sistemática do processo. Nesta perspectiva, os diversos estudos que têm apresentado a necessidade do desenvolvimento de habilidades associadas ao processo de investigação científica, para a compreensão da própria ciência, investigam e/ou propõem o desenvolvimento dessas habilidades em atividades específicas de ensino (WU, HSIEB, 2006; GOMES, 2005; BROOK, DRIVER, JOHNSTON, 1989).

A ênfase no desenvolvimento de habilidades se relaciona à necessidade de compreensão do processo acima da compreensão dos fatos. O aprendizado sobre os processos de investigação em ciências requer o desenvolvimento dessas habilidades, que são apresentadas de maneira bastante sucinta por Brook, Driver e Johnston (1989) e Wu e Hsieb (2006), como sendo: seleção e controle de variáveis, formulação de hipóteses, planejamento de procedimentos, interpretação de padrões de evidência, observação e comunicação dos resultados.

O aprendizado destas habilidades é defendido pelos documentos e estudos citados anteriormente, por serem 'habilidades transferíveis', que são "necessárias para a preparação dos jovens para o século XXI" (AAAS, 1989, p. 210). Isto se justifica pela crença de que, apesar de o conhecimento científico ser provisório, as habilidades e os processos científicos não o são (BROOK, DRIVER, JOHNSTON, 1989).

Nesta perspectiva, a condução de um ensino fundamentado em atividades de investigação se coloca como uma excelente oportunidade para favorecer o desenvolvimento das habilidades e compreensão do processo de construção da ciência, partes necessárias ao processo de desenvolvimento do próprio raciocínio do indivíduo. Tais habilidades poderão ser desenvolvidas ao longo das atividades de investigação e por meio da transferência dessas de um processo para o outro, momentos em que ocorrerá o aperfeiçoamento dessas habilidades.

$\mathrm{Na}$ prática em sala de aula, o desenvolvimento dessas habilidades dos estudantes deve ser acompanhado durante as atividades de investigação promovidas, fornecendo um feedback, tanto em relação ao aprendizado quanto em relação à contribuição das atividades para o mesmo. Contudo, a avaliação dessas habilidades constitui um ponto de grande complexidade, sendo necessário o desenvolvimento de um processo avaliativo coerente com o processo de ensino desenvolvido. 


\section{A avaliação do conhecimento frente às novas perspectivas de ensino}

A preocupação em relação à coerência entre o processo de avaliação e os objetivos definidos atualmente para o ensino de ciências tem sido retratada por vários estudos, sobretudo aqueles que acompanham as avaliações em massa realizadas em diversos países (PISA, 2004; BRASIL, 1999a; IES, 1997; TIMSS, 1996 ). Estes documentos, apesar de desenvolvidos em anos e em países diferentes, se aproximam em relação aos objetivos propostos para o ensino de ciências, com especial atenção para o desenvolvimento de habilidades associadas ao processo de investigação científica. Alguns deles trazem os objetivos de ensino avaliados de maneira bastante genérica e superficial, como ocorre no relatório do National Assessment of Educational Progress (NAEP) (IES, 2006), que apresenta apenas quatro habilidades gerais avaliadas nas questões do exame - identificação dos princípios da ciência, uso dos princípios da ciência, uso da investigação científica, uso de desenho tecnológico - ou, ainda, como o Programme for International Student Assessment (PISA), que apenas cita tais habilidades como "habilidades de raciocínio analítico" (PISA, 2004, p. 28).

Apesar da pouca clareza em relação às habilidades avaliadas por esses exames, é esperado que estas se refiram às habilidades envolvidas no processo de investigação científica, uma vez que isto seria a prática coerente com os objetivos dos mesmos e com a atual perspectiva para o ensino de ciências. Nesse sentido, as questões desses exames deveriam favorecer a explicitação dos conhecimentos dos estudantes relacionados ao processo de investigação científica. Além disso, relatórios sobre essas avaliações em massa afirmam consonância com as atuais perspectivas para o ensino de ciências e explicitam que procuram avaliar, além de conhecimentos declarativos, as habilidades desenvolvidas pelos estudantes ao longo do processo de aprendizagem.

Estas avaliações em massa, contudo, não devem ser vistas como instrumentos integrantes do processo de ensino, tendo valor reconhecidamente limitado ou mesmo inexpressivo em relação a este aspecto. Isto porque elas envolvem testes que são infreqüentes, isolados de contextos educacionais regulares, ocorrem em ocasiões especiais com rituais formais, e freqüentemente são conduzidas por métodos sobre os quais professores individuais têm pouco ou nenhum controle (BLACK et al., 2003). Os objetivos destas avaliações vinculam-se ao diagnóstico do que os alunos aprendem nas escolas, cujos resultados devem servir para o direcionamento específico das atividades e processos de ensino desenvolvidos em sala de aula, definição de políticas, ênfases e currículos futuros. Em outras palavras, o propósito destas avaliações é produzir um diagnóstico do sistema de avaliação desenvolvido por segmentos maiores (escolas, estados e países) - o que se distingue dos objetivos de avaliações realizadas no contexto de uma sala de aula.

A opção por analisar essas avaliações em massa neste trabalho relaciona-se à afirmação de que elas buscam coerência com os atuais propósitos do ensino de ciências; e ao fato de elas se apresentarem como diretrizes em relação ao ensino de ciências e ao próprio processo avaliativo a ser desenvolvido na área, conforme destacado pelo NAEP: 
Maia, P. F.; Justi, R.

Uma nova diretriz para guiar a avaliação no ensino de ciências é necessária por várias razões: a publicação de padrões nacionais para a alfabetização científica, avanços na pesquisa científica e cognitiva, crescimento na avaliação em ciências tanto em contexto nacional quanto internacional, e aumento ao acesso a avaliações inovadoras. (IES, 1997)

\section{A pesquisa}

\section{Amostra e objetivo}

Os programas de avaliação em massa desenvolvidos em todo o mundo têm apresentado relatórios que afirmam consonância com as diretrizes atuais para o ensino de ciências (por exemplo, TIMSS, 1996). Desta maneira, a inserção de questões com o intuito de avaliar os conhecimentos que se deseja desenvolver no ensino em ciências, sobretudo aquelas relacionadas às habilidades que devem ser desenvolvidas pelos estudantes, tem sido ressaltada por todos os programas de avaliação em massa.

Neste trabalho são analisadas as avaliações desenvolvidas por quatro programas de avaliação em massa de diversos países (ou grupo de países): Third International Mathematics and Science Study (TIMSS); Programme for International Student Assessment (PISA); National Assessment of Educational Progress (NAEP); Exame Nacional do Ensino Médio (ENEM). Em comum, eles apresentam o propósito de evidenciar um panorama do atual processo do desenvolvimento do conhecimento dos estudantes e, com isso, subsidiar novas propostas e apontar direções a serem tomadas no ensino. Contudo, as análises apresentadas por cada um desses programas variam em suas unidades de análise (escolas, cidades, países, faixa etária, nível socioeconômico), fatores considerados (sociais, econômicos, culturais, de gênero, entre outros), nível de escolaridade dos alunos avaliados e/ou período no ano letivo em que ocorre a aplicação destas avaliações. Todos estes programas envolvem, além da avaliação de conteúdos e habilidades, questionários socioeconômicos, avaliação de recursos pessoais e materiais das escolas, entre outros. O quadro 1 apresenta, de maneira sucinta, os objetivos e algumas das principais características dos programas de avaliação analisados, segundo os relatórios mais recentes destes programas.

O objetivo deste trabalho é apresentar uma análise das questões de ciências dos últimos exames disponibilizados ${ }^{4}$, aplicados por cada um dos quatro programas de avaliação em massa citados acima, identificando as habilidades avaliadas pelas questões e a consonância destas à atual perspectiva para o ensino de ciências. Os exames analisados compreenderam as séries $8 \mathrm{e} /$ ou 12 (equivalentes à $8^{\mathrm{a}}$ série do Ensino Fundamental e $3^{\mathrm{a}}$ série do Ensino Médio no Brasil).

${ }^{4}$ Questões disponibilizadas do NAEP 2006 (IES, 2006), ENEM 2006 (BRASIL, 2006), PISA 2003 e TIMSS 2003 (TIMSS, PIRLS, 2003). 
Desenvolvimento de habilidades no ensino...

Quadro 1. Programas de avaliação em massa e principais características.

\begin{tabular}{|c|c|c|c|c|}
\hline & $\begin{array}{l}\text { Número de } \\
\text { países } \\
\text { participantes }\end{array}$ & $\begin{array}{l}\text { Série(s) de } \\
\text { aplicação }\end{array}$ & $\begin{array}{c}\text { Formato da } \\
\text { avaliação escrita }\end{array}$ & Principais objetivos \\
\hline TIMSS & $\begin{array}{l}67 \text { países }^{1}, \\
\text { participantes ao } \\
\text { longo dos três } \\
\text { anos da } \\
\text { avaliação (1995, } \\
1999 \text { e 2003). No } \\
\text { ano de 2003, } \\
\text { constituinte da } \\
\text { análise deste } \\
\text { trabalho, } \\
\text { participaram } 49 .\end{array}$ & $\begin{array}{l}\text { Anos } 4 \text { e } 8 \text { da } \\
\text { escolarização } \\
\text { básica. }\end{array}$ & $\begin{array}{l}\text { De } 33 \text { a } 40 \% \text { das } \\
\text { questões envolvem } \\
\text { respostas abertas } \\
\text { e, as demais, de } \\
\text { múltipla escolha. }\end{array}$ & $\begin{array}{l}\text { Avaliar os estudantes em questões de } \\
\text { conteúdo (no caso de ciências, em } \\
\text { química, física, ciência da terra e ciência } \\
\text { ambiental) e de cognição (em ciências: } \\
\text { conhecimento de fatos, compreensão } \\
\text { conceitual, argumentação e análise). } \\
\text { Identificar fatores ou combinações de } \\
\text { fatores relacionados ao desempenho dos } \\
\text { estudantes na avaliação (por meio de } \\
\text { questionários sobre características } \\
\text { metodológicas e materiais das escolas, } \\
\text { formação dos professores, currículo e } \\
\text { aspectos sociais da família do aluno). }\end{array}$ \\
\hline NAEP & $\begin{array}{c}1 \text { país (Estados } \\
\text { Unidos) }\end{array}$ & $\begin{array}{c}\text { Anos } 4,8 \text { e } \\
12 \text { da } \\
\text { escolarização } \\
\text { básica. }\end{array}$ & $\begin{array}{c}\text { Questões de } \\
\text { múltipla escolha } \\
\text { (algumas com } \\
\text { justificativa) e } \\
\text { questões abertas, } \\
\text { igualmente } \\
\text { distribuídas nos } \\
\text { três formatos ao } \\
\text { longo da avaliação. }\end{array}$ & $\begin{array}{l}\text { Avaliar as condições e progressos da } \\
\text { nação na área da educação com base no } \\
\text { desempenho dos estudantes na } \\
\text { avaliação. Interpretar os resultados em } \\
\text { relação a outras características da } \\
\text { população, como: etnia, gênero e tipo de } \\
\text { escola (pública ou privada). } \\
\text { Sobre ciências, em específico, o objetivo } \\
\text { é avaliar conteúdos (ciência da terra, } \\
\text { ciência física, e ciência da vida) e três } \\
\text { elementos de saber e fazer ciência } \\
\text { (investigação compreensiva, científico- } \\
\text { conceitual, e prático-argumentativa), } \\
\text { envolvendo o entendimento sobre a } \\
\text { natureza da ciência. }\end{array}$ \\
\hline PISA & $\begin{array}{l}43 \text { países em } \\
2000,41 \text { em } \\
2003 \text { e } 57 \text { em } \\
2006^{2} \text { (ano cujo } \\
\text { teste foi } \\
\text { analisado neste } \\
\text { trabalho). }\end{array}$ & $\begin{array}{l}\text { Ano } 12 \text { (ou } \\
\text { correspondente } \\
\text { série final da } \\
\text { educação } \\
\text { básica). }\end{array}$ & $\begin{array}{c}\text { Questões de } \\
\text { múltipla escolha e } \\
\text { questões abertas, } \\
\text { distribuídas quase } \\
\text { que igualmente nos } \\
\text { dois formatos. }\end{array}$ & $\begin{array}{l}\text { Testar e determinar o preparo dos } \\
\text { estudantes em relação aos desafios de } \\
\text { suas vidas futuras. Em particular, avaliar } \\
\text { os níveis de leitura e letramento em } \\
\text { matemática e ciências, por meio da } \\
\text { avaliação de como, efetivamente, os } \\
\text { estudantes aplicam a leitura, habilidades } \\
\text { matemáticas e científicas e conhecimento } \\
\text { para resolver problemas em contextos do } \\
\text { mundo real. Em ciências, envolve a } \\
\text { avaliação de conceitos científicos e } \\
\text { processos aplicados a situações reais } \\
\text { desta área.A análise dos resultados da } \\
\text { avaliação é associada a características } \\
\text { do contexto, obtidas em questionários } \\
\text { sobre capital econômico, social e cultural } \\
\text { etc. }\end{array}$ \\
\hline
\end{tabular}


Maia, P. F; Justi, R.

Quadro 1. continuação

\begin{tabular}{|c|c|c|c|c|}
\hline ENEM & $\begin{array}{c}\text { Número de } \\
\text { países } \\
\text { participantes }\end{array}$ & $\begin{array}{c}\text { Série(s) de } \\
\text { aplicação }\end{array}$ & $\begin{array}{c}\text { Formato da } \\
\text { avaliação escrita }\end{array}$ & \multicolumn{1}{|c|}{ Principais objetivos } \\
\hline 1 país (Brasil). & $\begin{array}{c}\text { Ano 11 } \\
\text { (atualmente } \\
\text { 12) (último } \\
\text { ano da } \\
\text { escolarização } \\
\text { básica). }\end{array}$ & $\begin{array}{c}\text { Questões de } \\
\text { múltipla escolha e } \\
\text { redação. }\end{array}$ & $\begin{array}{l}\text { Avaliar o desenvolvimento do aluno e tudo } \\
\text { aquilo que o mesmo adquiriu durante o seu } \\
\text { curso, como: a competência de ler, } \\
\text { compreender, interpretar e produzir textos } \\
\text { no sentido amplo do termo, envolvendo } \\
\text { todas as áreas e disciplinas que compõem } \\
\text { a atividade pedagógica da escola. }\end{array}$ \\
\hline
\end{tabular}

${ }^{1}$ África do Sul, Alemanha, Arábia Saudita, Argentina, Armênia, Austrália, Áustria, Bahrain, Bélgica, Botswana, Bulgária, Canadá, Chile, Chipre, Cingapura, Colômbia, Dinamarca, Egito, Escócia, Eslovênia, Eslováquia, Espanha, Estados Unidos, Estônia, Inglaterra, Filipinas, Finlândia, França, Gana, Grécia, Holanda, Hong Kong, Hungria, Indonésia, Islândia, Irlanda, Israel, Itália, Japão, Jordan, Kuwait, Latvia, Líbano, Lituânia, Macedônia, Malásia, Marrocos, Nova Zelândia, Noruega, Palestina, Portugal, República da Coréia, República da Maldóvia, República do Irã, República Tcheca, Romênia, Rússia, Sérvia, Suécia, Suíça, Síria, Tailândia, Taiwan, Turquia, Yemen.

${ }^{2}$ Albânia, Alemanha, Argentina, Austrália, Áustria, Azerbaijão, Bélgica, Brasil, Bulgária, Canadá, Casaquistão, Chile, China, Colômbia, Coréia, Croácia, Dinamarca, Eslováquia, Eslovênia, Espanha, Estados Unidos, Estônia, Finlândia, França, Grécia, Holanda, Hong Kong, Hungria, Indonésia, Islândia, Israel, Irlanda, Itália, Japão, Jordânia, Qatar, Latvia, Lituânia, Luxemburgo, Macedônia, México, Noruega, Nova Zelândia, Peru, Polônia, Portugal, Sérvia e Montenegro, Suécia, Suíça, Reino Unido, República Tcheca, Rússia, Tailândia, Taiwan, Tunísia, Turquia, Uruguai.

\section{A análise}

A análise realizada neste trabalho fez uso de itens disponibilizados ${ }^{5}$ na íntegra pelos quatro programas, ocorrendo de forma parcial em relação ao TIMSS 2003 (TIMSS, PIRLS, 2003) e ao PISA 2004. A indisponibilidade de todas as questões dos mesmos é justificada pelos próprios programas em função da possibilidade de utilização das questões em avaliações futuras. Com isto, em especial, a análise do PISA 2004 apresenta um número bastante reduzido de questões. Contudo, esta é uma limitação inerente à impossibilidade de acesso às demais questões. Apesar disso, este trabalho se propõe a realizar tal análise, uma vez que os próprios relatórios oficiais afirmam que os itens disponibilizados constituem uma amostra representativa do conteúdo dessas avaliações.

O quadro 2 apresenta o número de questões de ciências presentes em cada uma das avaliações analisadas neste trabalho.

\footnotetext{
${ }^{5}$ As questões analisadas podem ser acessadas nos sítios eletrônicos dos respectivos programas de avaliação, a partir dos endereços eletrônicos disponibilizados na seção Referências Bibliográficas deste trabalho.
} 
Desenvolvimento de habilidades no ensino...

Quadro 2. Número de questões analisadas das avaliações correspondentes.

\begin{tabular}{|c|c|c|}
\hline Avaliações & Nível de ensino de aplicação & Número de questões de Ciências \\
\hline TIMSS, PIRLS 2003 & Ano 8 & 95 \\
\hline NAEP 2006 & Ano 8 & 90 \\
\cline { 2 - 3 } & Ano 12 & 80 \\
\hline PISA 2003 & Ano 8 & 5 \\
\hline ENEM 2006 & 3a série, Ensino Médio & $15^{1}$ \\
\hline
\end{tabular}

${ }^{1}$ Uma vez que o ENEM não apresenta separação explícita de conteúdos por disciplinas, nesta análise foram consideradas todas as questões que envolviam conhecimentos prévios exclusivos de biologia, química ou física ou, ainda, questões cuja resolução promovia o desenvolvimento de algum conhecimento restrito a estas áreas. Desta maneira, questões relativas a aspectos ambientais, passíveis de serem respondidas com conhecimentos derivados da interpretação de gráficos ou de processos de uso e ocupação do meio ambiente (sem requerer conhecimentos específicos abordados exclusivamente nas disciplinas de Ciências) não foram incluídas. As demais avaliações apresentavam blocos de questões atribuídas à área de Ciências.

A análise de cada uma das questões das avaliações foi realizada de forma qualitativa, e a confiabilidade da análise foi buscada por meio da triangulação entre as autoras deste trabalho (COHEN, MANION, MORRISON, 2000), que analisaram cada uma das questões individual e separadamente e, em seguida, discutiram as diferenças de análise até o estabelecimento de um consenso.

A análise foi realizada em dois momentos distintos, que se prestaram a classificar a exigência das questões em termos de conhecimento e habilidades, respectivamente.

No primeiro momento da análise, foram separadas as questões que requeriam apenas conhecimentos declarativos e compreensão de informações para sua resolução, daquelas que envolviam o uso de outros conhecimentos e habilidades. Para isto, foi usada como parâmetro a classificação de questões apresentada pelos relatórios do TIMSS, em que estas são selecionadas em grupos de acordo com o conhecimento exigido em sua resolução: conhecimento de fatos, compreensão de conceitos e raciocínio e análise.

Para a classificação das questões dos demais exames nesses três grupos apresentados, cada autora analisou a classificação apresentada pelo TIMSS e, posteriormente, elas discutiram e ponderaram os critérios que seriam adotados na categorização das demais questões.

Com o propósito de explicitar os critérios adotados para esta primeira etapa de análise, cada uma das categorias - 'conhecimento de fatos', 'compreensão de conceitos' e 'raciocínio e análise' - é exemplificada com questões do exame TIMSS e PIRLS, 2003, que evidenciam os critérios adotados neste trabalho para identificar o tipo de conhecimento exigido em cada questão e proceder com a categorização.

\section{Categoria: Conhecimento de fatos}

A resolução de questões classificadas nesta categoria exige apenas o acesso a conhecimentos prévios e/ou informações disponibilizadas pelo enunciado da própria questão, havendo aplicação direta deste conhecimento de forma declarativa. 
Maia, P. F.; Justi, R.

Uma toalha molhada secará quando deixada ao Sol.

Qual processo ocorre para que isto aconteça?

a) solidificação

b) ebulição

c) condensação

d) evaporação

Figura 2. Exemplo de questão de conhecimento de fatos extraída do exame TIMSS, PIRLS, 2003.

\section{Categoria: Compreensão de conceitos}

Questões que exigem compreensão de conceitos fornecem contextos de aplicação do conhecimento prévio do estudante de forma problematizada, ou seja, o estudante deverá mobilizar os conceitos aprendidos na elaboração de respostas frente a uma situação problema.
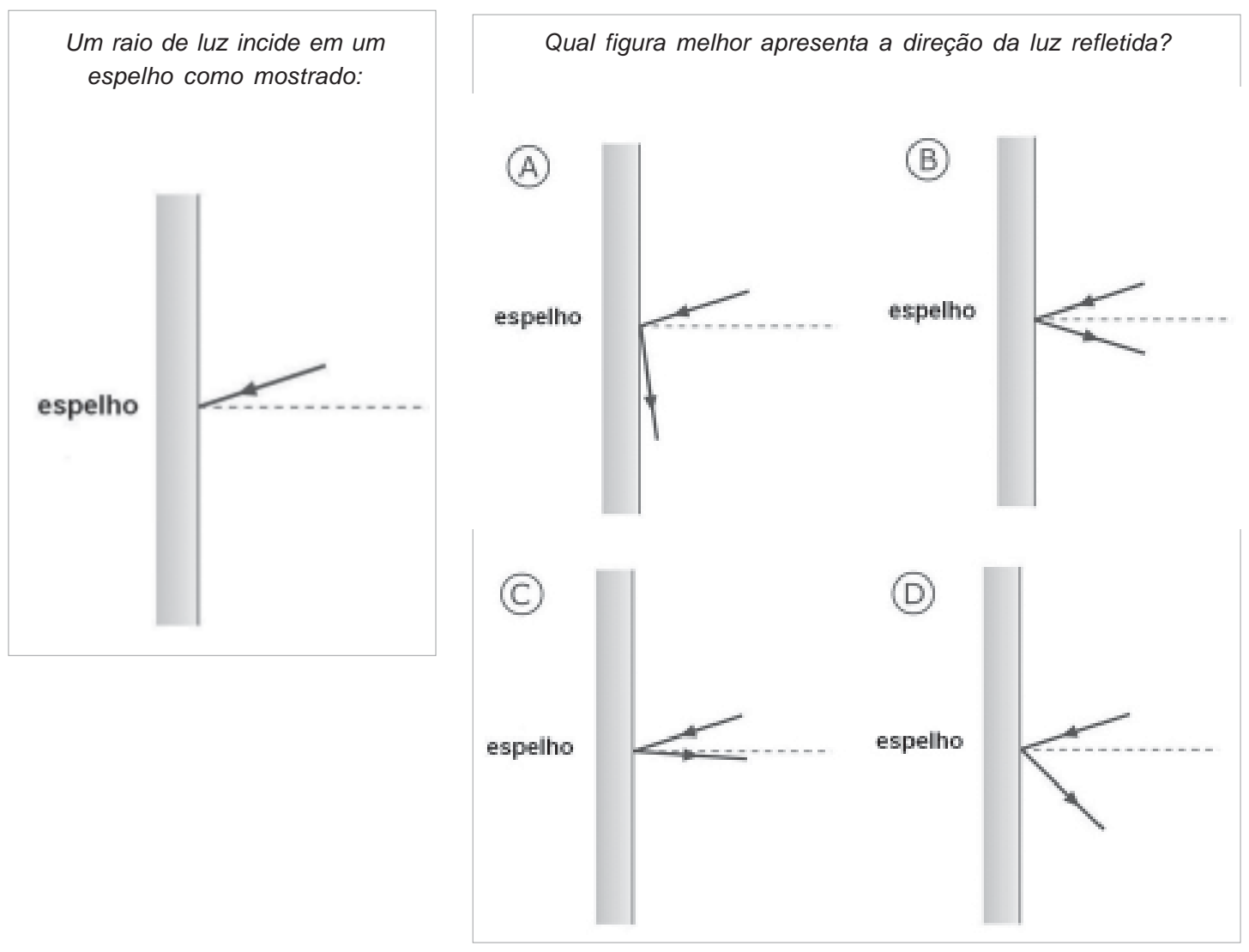

Figura 3. Exemplo de questão de compreensão de conceitos extraída do exame TIMSS, PIRLS, 2003. 


\section{Categoria: Raciocínio e análise}

Para a resolução de questões que exigem raciocínio e análise, o estudante deverá selecionar, em sua estrutura cognitiva, os conhecimentos prévios necessários e integrá-los para a elaboração de uma resposta a um problema que é, em geral, inédito. Neste grupo se enquadram questões de análise de gráficos e tabelas, pois estas exigem a interpretação e correlação de dados para a elaboração de asserções que são específicas do contexto.

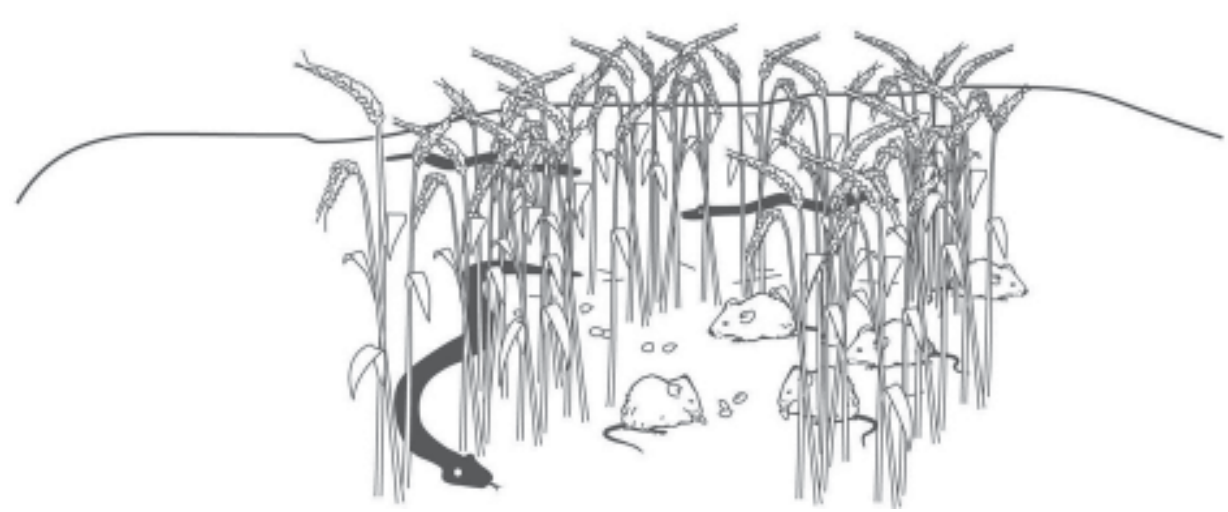

O diagrama acima mostra uma comunidade constituída de ratos, cobras e pés de trigo. O que aconteceria a esta comunidade se pessoas matassem as cobras?

Figura 4. Exemplo de questão de raciocínio e análise extraída do exame TIMSS, PIRLS, 2003.

No segundo momento da análise, todas as questões que exigiram "entendimento de conceitos" e "raciocínio e análise", por serem consideradas capazes de retratar melhor os conhecimentos exigidos no processo de investigação científica, foram analisadas com o objetivo de identificar as habilidades envolvidas na resolução das mesmas. Para tanto, posteriormente foram definidas, de forma mais detalhada, as habilidades mais freqüentemente requeridas em um processo de investigação. Isto aconteceu em duas etapas. Inicialmente, foram listadas todas as habilidades envolvidas em um processo de investigação, apontadas por diversos documentos (como, por exemplo, BRASIL, 2002; BROOK, DRIVER, JOHNSTON, 1989). Em seguida, tais habilidades foram relacionadas às etapas do processo de investigação apresentadas no ciclo de investigação (Figura 1). Os relacionamentos obtidos são apresentados no Quadro 3.

Neste segundo momento de análise, após uma discussão entre as pesquisadoras para a atribuição do significado de cada habilidade e determinação de como ela poderia ser identificada em uma questão, foram relacionadas todas as habilidades necessárias para a resolução de cada uma das questões. A este processo de análise sucedeu-se o processo de triangulação, conforme previamente descrito. 
Maia, P. F.; Justi, R.

Quadro 3. Habilidades relacionadas ao processo de investigação.

\begin{tabular}{|l|l|}
\hline Etapa do processo de investigação & \multicolumn{1}{c|}{ Habilidades envolvidas } \\
\hline $\begin{array}{l}\text { Questões (Definição dos objetivos do } \\
\text { processo) }\end{array}$ & $\begin{array}{l}\text { Analisar e compreender a situação-problema.Sistematizar o } \\
\text { problema por meio da formulação de questões. }\end{array}$ \\
\hline \multirow{2}{*}{ Informações } & $\begin{array}{l}\text { Conhecer diferentes formas de obter informações.Selecionar } \\
\text { conhecimentos prévios relevantes (na estrutura } \\
\text { cognitiva).Buscar informações já disponíveis na } \\
\text { literatura.Identificar propriedades relevantes do sistema em } \\
\text { estudo.Observar propriedades relevantes do sistema em } \\
\text { estudo. Descrever sistemas e processos. Relacionar } \\
\text { fenômenos, fatos, processos e idéias. }\end{array}$ \\
\hline Investigação & $\begin{array}{l}\text { Integrar idéias, dados e modelos.Elaborar novos } \\
\text { conhecimentos, tendo em vista os objetivos definidos } \\
\text { anteriormente. Elaborar questões hipotéticas.Planejar } \\
\text { experimentos adequados, identificando variáveis relevantes } \\
\text { e selecionando os procedimentos.Utilizar instrumentos de } \\
\text { medição e de cálculo. Coletar, analisar e interpretar os dados. }\end{array}$ \\
\hline Modelo & $\begin{array}{l}\text { Utilizar e interpretar diferentes formas de expressão e } \\
\text { representação. }\end{array}$ \\
\hline Análise & $\begin{array}{l}\text { Analisar os resultados obtidos e as implicações dos mesmos. } \\
\text { Analisar a extensão em que o modelo proposto atinge seus } \\
\text { objetivos. Estabelecer relações entre o modelo proposto e um } \\
\text { contexto mais amplo, envolvendo novas situações e/ou } \\
\text { informações. }\end{array}$ \\
\hline Comunicação & $\begin{array}{l}\text { Comunicar idéias com correção e clareza, fazendo uso de } \\
\text { terminologias adequadas. }\end{array}$ \\
\hline &
\end{tabular}

É importante considerar que a relevância da compreensão e aplicação direta de conhecimentos declarativos no processo de investigação científica não foi descartada ou subjugada nesta análise. Contudo, questões que exigiam exclusivamente esses conhecimentos, não requerendo habilidades específicas para a resolução das mesmas, não necessitariam ser incluídas na segunda etapa da análise.

\section{Resultados e discussão}

Os resultados da primeira etapa de análise das questões são apresentados na tabela 1, que relaciona o número e o percentual de questões de cada avaliação aos conhecimentos exigidos na resolução das mesmas.

A tabela 1 evidencia uma freqüência equilibrada entre os conhecimentos exigidos nas questões. Contudo, uma análise do conteúdo dessas questões evidencia que, apesar de cerca de apenas um terço delas exigirem exclusivamente conhecimentos de fatos, questões de "compreensão de conceitos" freqüentemente exigiam conhecimentos declarativos (cerca de 25\% das questões desta categoria). 
Desenvolvimento de habilidades no ensino...

Tabela 1. Distribuição de questões segundo os conhecimentos exigidos.

\begin{tabular}{|c|c|c|c|c|c|c|}
\hline \multirow[t]{2}{*}{ Avaliação } & \multicolumn{2}{|c|}{ Conhecimento de fatos } & \multicolumn{2}{|c|}{ Compreensão de conceitos } & \multicolumn{2}{|c|}{ Raciocínio e análise } \\
\hline & $n^{\circ}$ & $\%$ & $n^{\circ}$ & $\%$ & $n^{\circ}$ & $\%$ \\
\hline TIMSS Ano 8 & 26 & 27 & 39 & 41 & 30 & 32 \\
\hline NAEP Ano 8 & 25 & 28 & 28 & 31 & 37 & 41 \\
\hline NAEP Ano 12 & 23 & 28 & 27 & 34 & 30 & 38 \\
\hline PISA & 3 & 60 & 1 & 20 & 1 & 20 \\
\hline ENEM & 4 & 27 & 2 & 13 & 9 & 60 \\
\hline Total & 81 & 28 & 97 & 34 & 107 & 38 \\
\hline
\end{tabular}

Tais conhecimentos, apesar de relevantes para o desenvolvimento das idéias dos estudantes e para o próprio conhecimento em ciências, apareceram, em grande parte, de forma descontextualizada. Isto está em desacordo com os propósitos traçados atualmente para o ensino de ciências, em que os conhecimentos desenvolvidos devem ser aplicáveis, contribuindo para a formação dos estudantes como cidadãos e para o desenvolvimento de um conhecimento mais amplo.

Apesar de algumas questões relativas à compreensão de conceitos estarem relacionadas à explicitação de conhecimentos declarativos, no geral, esta categoria envolveu um nível mais elevado de exigência cognitiva, requerendo a explicitação de um conhecimento mais depurado, pelo estudante, no processo de interpretação da questão e do conteúdo abordado.

As questões de raciocínio e análise apresentaram maior proximidade em relação às demandas atuais de ensino. Tais questões apresentaram situações-problema cotidianas e exigiram raciocínio lógico, mesmo requerendo, ao mesmo tempo, conhecimentos específicos de conteúdo. As questões desta categoria que apresentaram mais êxito em relação à coerência aos objetivos de ensino foram as do tipo abertas. Estas, além de exigir a explicitação da habilidade de comunicação e representação, abordaram problemas mais investigativos, com a possibilidade de uma mesma questão requerer diferentes habilidades em sua resolução. Isto destaca a relevância da exigência de respostas abertas no processo de avaliação de habilidades.

A Tabela 2 apresenta um panorama da freqüência de cada habilidade na resolução das questões das avaliações. A soma do número de questões em cada coluna é superior ao número de questões categorizadas, na tabela 1 , como questões de "compreensão de conceitos" e "raciocínio e análise", devido à exigência de múltiplas habilidades em algumas questões.

A análise da Tabela 2 permite identificar que as habilidades requeridas para a resolução das questões se concentram na compreensão do objeto de estudo e na reunião de informações sobre ele. Contudo, a maioria das questões exigia, em suas resoluções, o emprego de idéias e modelos previamente construídos. Assim, em grande parte, elas não contemplavam a utilização de atividades com o intuito investigativo ou, pelo menos, não de maneira mais ampla, envolvendo o ciclo de investigação. Desta forma, as questões se aproximavam apenas das partes iniciais de um processo investigativo, correspondentes à definição da abordagem do problema e seleção de informações necessárias. Um exemplo de questão desta natureza é apresentado na Figura 5, em que são avaliadas estritamente as habilidades de identificar propriedades relevantes do sistema em estudo e relacionar estas propriedades ao fenômeno descrito. 
Maia, P. F.; Justi, R.

Tabela 2. Número de questões, por avaliação, que exigia as habilidades relacionadas.

\begin{tabular}{|c|c|c|c|c|c|c|c|c|c|c|c|c|}
\hline \multirow{2}{*}{ Habilidades } & \multicolumn{2}{|c|}{ TIMSS 8} & \multicolumn{2}{|c|}{ NAEP 8} & \multicolumn{2}{|c|}{ NAEP 12} & \multicolumn{2}{|c|}{ PISA } & \multicolumn{2}{|c|}{ ENEM } & \multicolumn{2}{|c|}{ Total } \\
\hline & $n^{\circ}$ & $\%$ & $\mathbf{n}^{\circ}$ & $\%$ & $n^{\circ}$ & $\%$ & $n^{\circ}$ & $\%$ & $\mathrm{n}^{\circ}$ & $\%$ & $\mathbf{n}^{\circ}$ & $\%$ \\
\hline $\begin{array}{l}\text { Analisar e compreender a situação- } \\
\text { problema }\end{array}$ & 40 & 58 & 46 & 69 & 44 & 77 & 2 & 100 & 11 & 100 & 143 & 70 \\
\hline $\begin{array}{l}\text { Sistematizar o problema/formular } \\
\text { questões }\end{array}$ & 29 & 42 & 35 & 54 & 29 & 51 & 1 & 50 & 4 & 36 & 98 & 48 \\
\hline Identificar propriedades relevantes & 18 & 26 & 35 & 54 & 23 & 40 & 1 & 50 & 6 & 54 & 83 & 41 \\
\hline Descrever sistemas e processos & 10 & 15 & 33 & 51 & 25 & 44 & 1 & 50 & 2 & 18 & 71 & 35 \\
\hline $\begin{array}{l}\text { Relacionar fenômenos, fatos, } \\
\text { processos e idéias }\end{array}$ & 31 & 45 & 42 & 65 & 28 & 49 & 2 & 100 & 10 & 91 & 113 & 55 \\
\hline $\begin{array}{l}\text { Aplicar conhecimento prévio na } \\
\text { resolução de situação- problema }\end{array}$ & 37 & 54 & 35 & 54 & 27 & 47 & 1 & 50 & 4 & 36 & 104 & 51 \\
\hline $\begin{array}{l}\text { Elaborar novos conhecimentos como } \\
\text { resultado da resolução da questão }\end{array}$ & 3 & 4 & 6 & 9 & 11 & 19 & 0 & 0 & 3 & 27 & 23 & 11 \\
\hline Elaborar questões hipotéticas & 24 & 35 & 23 & 35 & 16 & 28 & 2 & 100 & 3 & 27 & 68 & 33 \\
\hline $\begin{array}{l}\text { Planejar experimentos adequados, } \\
\text { identificando variáveis relevantes e } \\
\text { selecionando os procedimentos }\end{array}$ & 3 & 4 & 6 & 9 & 2 & 4 & 0 & 0 & 0 & 0 & 11 & 5 \\
\hline $\begin{array}{l}\text { Utilizar instrumentos de medição e de } \\
\text { cálculo }^{1}\end{array}$ & 5 & 7 & 0 & 0 & 2 & 4 & 0 & 0 & 0 & 0 & 7 & 3 \\
\hline Coletar, analisar e interpretar dados & 14 & 20 & 8 & 12 & 9 & 16 & 0 & 0 & 6 & 54 & 37 & 18 \\
\hline $\begin{array}{l}\text { Utilizar e interpretar diferentes formas } \\
\text { de expressão e representação }\end{array}$ & 26 & 38 & 20 & 31 & 17 & 30 & 1 & 50 & 7 & 64 & 71 & 35 \\
\hline $\begin{array}{l}\text { Analisar os resultados obtidos e as } \\
\text { implicações dos mesmos }\end{array}$ & 9 & 13 & 2 & 3 & 1 & 2 & 1 & 50 & 3 & 27 & 16 & 8 \\
\hline $\begin{array}{l}\text { Analisar a extensão em que o modelo } \\
\text { proposto atinge seus objetivos }\end{array}$ & 0 & 0 & 5 & 8 & 5 & 9 & 0 & 0 & 0 & 0 & 10 & 5 \\
\hline $\begin{array}{l}\text { Estabelecer relações entre o modelo } \\
\text { proposto e um contexto mais amplo, } \\
\text { envolvendo novas situações e/ou } \\
\text { informações }\end{array}$ & 11 & 16 & 6 & 9 & 9 & 16 & 2 & 100 & 1 & 9 & 29 & 14 \\
\hline $\begin{array}{l}\text { Comunicar idéias com correção e } \\
\text { clareza, fazendo uso de terminologias } \\
\text { adequadas }\end{array}$ & 27 & 39 & 42 & 65 & 35 & 61 & 1 & 50 & 0 & 0 & 105 & 51 \\
\hline Total de questões analisadas & 95 & 100 & 90 & 100 & 80 & 100 & 2 & 100 & 11 & 100 & 204 & 100 \\
\hline
\end{tabular}

${ }^{1}$ Dada a impossibilidade do uso de instrumentos de medida dentro do contexto destas avaliações, foram inseridas aqui as questões que exigiam a descrição sobre a utilização destes instrumentos.

Dentre as avaliações analisadas, o NAEP e o TIMSS contemplaram, de maneira mais ampla, a exigência de habilidades diversas, aproximando as questões constituintes destas avaliações de atividades investigativas. Isto foi observado, sobretudo, pelo número de questões que forneciam oportunidades de formular hipóteses e analisá-las. Um exemplo é apresentado na questão da Figura 6, em que o estudante deve propor um mecanismo mais adequado de teste de suas hipóteses por meio da proposição de uma montagem experimental que envolve identificação e controle de variáveis. 
Desenvolvimento de habilidades no ensino...

Na região sul da Bahia, o cacau tem sido cultivado por meio de diferentes sistemas. Em um deles, o convencional, a primeira etapa de preparação do solo corresponde à retirada da mata e à queimada dos tocos e das raízes. Em seguida, para o plantio da quantidade máxima de cacau na área, os pés de cacau são plantados próximos uns dos outros. No cultivo pelo sistema chamado cabruca, os pés de cacau são abrigados entre as plantas de maior porte, em espaço aberto criado pela derrubada apenas das plantas de pequeno porte. Os cacaueiros dessa região têm sido atacados e devastados pelo fungo chamado vassoura-de-bruxa, que se reproduz em ambiente quente e úmido por meio de esporos que se espalham no meio aéreo. As condições ambientais em que os pés de cacau são plantados e as condições de vida do fungo vassoura-de-bruxa, mencionadas acima, permitem supor que sejam mais intensamente atacados por esse fungo os cacaueiros plantados por meio do sistema.

a) convencional, pois os pés de cacau ficam mais expostos ao sol, o que facilita a reprodução do parasita.

b) convencional, pois a proximidade entre os pés de cacau facilita a disseminação da doença. c) convencional, pois o calor das queimadas cria as condições ideais de reprodução do fungo.

d) cabruca, pois os cacaueiros não suportam a sombra e, portanto, terão seu crescimento prejudicado e adoecerão.

e) cabruca, pois, na competição com outras espécies, os cacaueiros ficam enfraquecidos e adoecem mais facilmente.

Figura 5. Questão do ENEM 2006 (BRASIL, 2006).

Este maior número de questões com caráter investigativo pode estar associado ao elevado número de questões destas avaliações (o que cria mais contextos para a avaliação de habilidades diversas) e, sobretudo, ao maior número de questões abertas presentes nas mesmas (que permitem a formulação de respostas mais complexas, exigindo a utilização de habilidades diversas na resolução de uma questão, conforme pode ser observado na Figura 4).

O NAEP merece especial destaque pelo uso de questões envolvendo a abordagem de um mesmo sistema ou processo em diversos contextos. Nestas questões ficou evidente a possibilidade de, gradualmente, se avaliarem as etapas de um processo investigativo por meio da disponibilidade de novas informações e novos contextos. Estas questões permitem a explicitação do modelo elaborado (ou usado) pelos alunos, havendo momentos em que foi dada a eles a oportunidade de analisar os próprios modelos utilizados.

Questões envolvendo a elaboração e implementação de testes com coleta de dados são inviáveis no contexto destas avaliações. Mas acreditamos que estas habilidades podem ser avaliadas, mesmo que de forma limitada, a partir da descrição desses procedimentos pelos alunos. Isto foi verificado em questões abertas do TIMSS e NAEP, como exemplificado na Figura 7.

A análise também evidenciou a menor freqüência de questões que exigem análise dos conhecimentos e modelos apresentados pelos alunos nas questões. Apenas duas questões do NAEP (uma questão na avaliação de cada segmento de ensino), dentre todas aquelas analisadas, envolveram conhecimentos específicos sobre modelos e seu processo de construção. Abrangendo explicitamente o processo de construção do conhecimento científico, foram identificadas apenas mais três questões, também do NAEP. Isto aparece como uma lacuna nestas avaliações, dada a relevância da abordagem destas temáticas para o desenvolvimento do conhecimento sobre o fazer ciência. 
Maia, P. F.; Justi, R.

Uma garota tem a idéia de que plantas verdes precisam de areia no solo para crescerem saudáveis. Para testar sua idéia, ela usa dois vasos de plantas. Um deles é montado como mostrado a seguir.

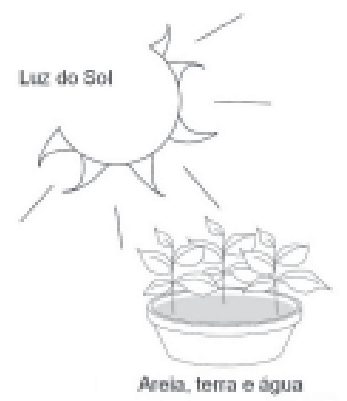

Qual das opções ela deveria usar para a montagem do segundo vaso de plantas?
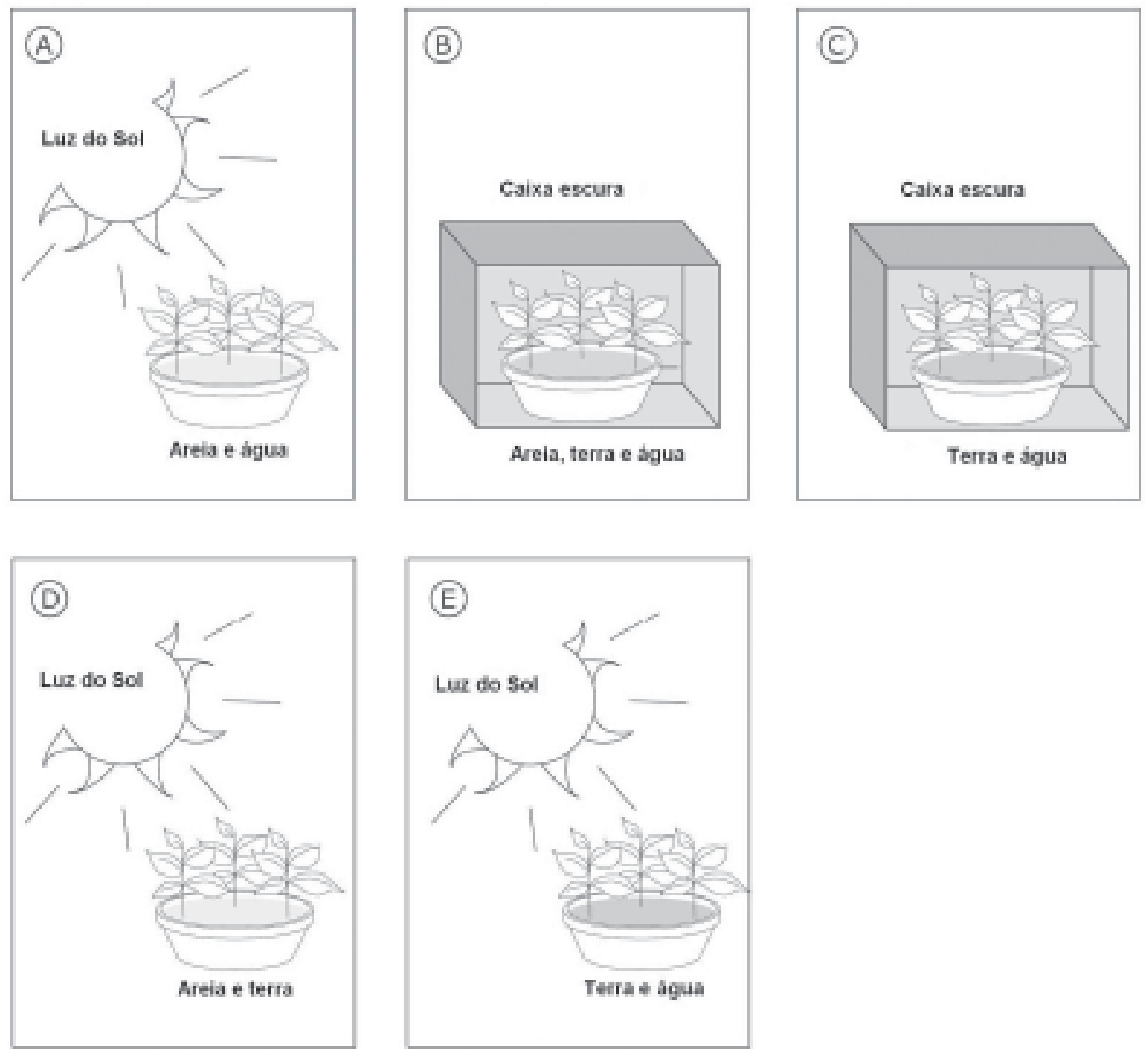

Figura 6. Questão do TIMS, PIRLS, 2003. 
Desenvolvimento de habilidades no ensino...

Um navio-tanque derramou óleo sobre a água. Investigadores querem saber se o movimento da onda ajudará na dispersão do óleo. Projete uma experiência que eles possam realizar em um laboratório para descobrir se o movimento da onda ajudará que o óleo se disperse. Descreva o equipamento que eles deveriam usar e o procedimento que eles deveriam seguir.

Equipamento:

Procedimento:

Figura 7. Questão do NAEP 2006 (IES, 2006), ano 12.

O ENEM, por sua vez, apesar de apresentar exclusivamente questões de múltipla escolha - o que limitou a exigência de diversas habilidades (sobretudo a comunicação de conhecimentos) - apresentou o maior percentual de questões que exigiram raciocínio e análise, o que está de acordo com a avaliação de um conhecimento contextualizado, coerente com os atuais parâmetros para o ensino de ciências vigentes no Brasil.

\section{Conclusões e implicações}

As avaliações em massa são instrumentos por meio dos quais se deseja identificar os processos e conteúdos que têm sido trabalhados no ensino, verificando a contribuição do ensino para o desenvolvimento de conhecimentos almejados para os estudantes. Desta forma, é possível afirmar que essas avaliações devem espelhar os próprios parâmetros estabelecidos para o ensino.

A análise realizada neste trabalho evidenciou a dificuldade de avaliação de habilidades de investigação, especialmente aquelas relacionadas às etapas de 'elaboração de modelo', 'análise' e 'comunicação' do ciclo de investigação, apresentando poucas oportunidades para a explicitação de conhecimentos a elas relacionados. Contudo, apesar do grande número de questões envolvendo o uso de conhecimentos declarativos, é possível perceber um movimento destas avaliações no sentido de contemplar os processos envolvidos na construção da ciência (mesmo que de forma ainda limitada), por meio da identificação da presença de questões que contemplam o uso de habilidades relacionadas ao conhecimento estratégico.

Apesar de a presente análise focar as habilidades que se espera que os alunos desenvolvam no ensino de ciências, não se defende aqui o uso de questões que estejam desvinculadas de conteúdos específicos, mesmo porque é sabido que as atividades que ajudam a desenvolver o conhecimento sobre o processo de construção da ciência envolvem a integração de conhecimentos prévios dos estudantes (BROOK, DRIVER, JOHNSTON, 1989). Em outras palavras, o conhecimento estratégico depende do conhecimento conceitual prévio como prérequisito para que, a partir deste, o estudante seja capaz de resolver o problema que está sendo 
Maia, P. F.; Justi, R.

apresentado. O que defendemos é que a avaliação pode ser realizada dentro de conteúdos específicos, mas deve apresentar questões que permitam avaliar, além do conhecimento sobre o conteúdo, habilidades e conhecimento sobre o processo de construção da ciência.

As avaliações de massa, assim como qualquer outra avaliação escrita, são instrumentos que devem conter questões que permitam aos estudantes explicitar suas idéias, envolvendo contextos nos quais eles possam transferir um conhecimento e/ou habilidade para novas situações-problema. Isto torna válido o uso de questões abertas - envolvendo problemas nos quais os estudantes deverão aplicar e explicitar o conhecimento que está sendo requerido. Tais questões devem ser contextualizadas - cobrando um conhecimento estratégico, e não apenas declarativo - e apresentar exigências coerentes com o que se deseja avaliar. A potencialidade da explicitação de maior número de habilidades por meio do uso de questões abertas - em especial a habilidade de comunicação de idéias e uso de diferentes formas de expressão - fica evidente ao se observar a avaliação dessas habilidades nos exames que apresentam esse tipo de questão.

As avaliações analisadas neste trabalho, apesar de evidenciarem certa coerência com as atuais perspectivas de ensino e, ao mesmo tempo, apresentarem questões que envolvem a avaliação de certas habilidades, se apresentam, ainda, diante de um grande caminho a percorrer. Isto está associado à necessidade de essas avaliações contemplarem, de maneira mais ampla, as diversas etapas envolvidas em atividades de investigação, para que elas sejam capazes de identificar, de maneira mais fiel, o sucesso do ensino no sentido de desenvolver uma visão adequada da ciência, seus processos e sua construção.

\section{Agradecimento}

Ao CNPq.

\section{Referências}

AAAS. American Association for the Advancement of Science. Science for all americans: a Project 2061 report on literacy goals in science, mathematics, and technology. Washington: AAAS, 1989.

BARAB, S. A. et al. Virtual solar system project: building understanding trough model building. Journal of Research in Science Teaching, Maryland, v. 37, p. 719-56, 2000.

BLACK, P. et al. Assessment for learning. New York: Open University Press, 2003.

BORGES, A. T. Novos rumos para o laboratório escolar de ciências. Caderno Brasileiro de Ensino de Física, Florianópolis, v. 19, n. 3, p. 291-313, 2002. 
Desenvolvimento de habilidades no ensino...

BRASIL. Exame Nacional do Ensino Médio 2006. Instituto Nacional de Estudos e Pesquisas Educacionais Anísio Teixeira, Ministério da Educação e da Cultura, 2006. Disponível em: <http://www.enem.inep.gov.br>. Acesso em: 15 out. 2007

PCN+ do Ensino Médio: ciências da natureza, matemática e suas tecnologias. Brasília: Ministério da Educação e do Desporto, 2002.

Exame Nacional do Ensino Médio. Documento Básico. Brasília: Ministério da Educação e da Cultura, 1999a. Disponível em: <http://www.enem.inep.gov.br>. Acesso em: 15 out. 2007.

Parâmetros Curriculares Nacionais do Ensino Médio: ciências da natureza, matemática e suas tecnologias. Brasília: Ministério da Educação e do Desporto, 1999b.

BROOK, A.; DRIVER, R.; JOHNSTON, K. Learning process in science: a classroom perspective. In: WELLINGTON, J. (Ed.). Skills and processes in science education: a critical analysis. London/New York: Routledge, 1989. p. 63-82.

CLEMENT, J. Model based learning as a key research area for science education.

International Journal of Science Education, Reading, v. 22, p. 1041-53, 2000.

COHEN, L.; MANION, L.; MORRISON, K. Research methods in education. London: Routledge Falmer, 2000.

FERREIRA, P. F. M. Modelagem e suas contribuições para o ensino de Ciências: uma análise no estudo de equilíbrio químico. 2006. 155f. Dissertação (Mestrado) -

Faculdade de Educação, Universidade Federal de Minas Gerais, Belo Horizonte, 2006.

GILBERT, J. K.; BOULTER, C. J.; ELMER, R. Positioning models in science education and in design and technology education. In: ___ _ _ _ (Eds.). Developing models in science education. Dordrecht: Kluwer, 2000. p. 3-18.

GOMES, A. D. T. Reconhecimento e uso de testes experimentais no laboratório escolar. 2005. 183f. Dissertação (Mestrado) - Faculdade de Educação, Universidade Federal de Minas Gerais, Belo Horizonte, 2005.

INSTITUTE OF EDUCATION SCIENCE. IES. Assessment Science Public Release. Washington: U.S. Government Printing Office, 2006. Disponível em: $<$ http://nces.ed.gov $>$. Acesso em: 15 out. 2007.

The NAEP guide: a description of the content and methods of the 1997 and 1998 assessments. Washington: U.S. Government Printing Office, 1997. Disponível em: $<$ http://nces.ed.gov/naep3>. Acesso em: 15 out. 2007.

MILLAR, R.; OSBORNE, J. Beyond 2000: science education for the future. London: King's College London School of Education, 1998.

PROGRAMME FOR INTERNATIONAL STUDENT ASSESSMENT. Problem solving for tomorrow's world first measures of cross-curricular competencies from PISA 2003. OECD, 2004. Disponível em: <http://www.pisa.oecd.org>. Acesso em: 15 out. 2007. 
Maia, P. F.; Justi, R.

SCHWARZ, C. V.; WHITE, B. Y. Metamodeling knowledge: developing students' understanding of scientific modeling. Cognition and Instruction, Connecticut, v. 23, n. 2, p. $165-205,2005$.

TIMSS. International Study Center TIMSS. Third International Mathematics and Science Study Technical Report: design and development. Chestnut Hill: Boston College, 1996. v. 1. Disponível em: <http://nces.ed.gov/timss>. Acesso em: 15 out. 2007.

.; PIRLS International Study Center. Third International Mathematics and Science 2003: sample questions. Chestnut Hill: Boston College, 2003. Disponível em: <http://nces.ed.gov/timss>. Acesso em: 15 out. 2007.

WU, H. K.; HSIEB, C. E. Developing sixth graders' inquiry skills to construct explanations in inquiry-based learning environments. International Journal of Science Education, Reading, v. 28, n. 11, 2006. p. 1289-313.

Artigo recebido em novembro de 2007 e aprovado em março de 2008. 